\title{
HIV infection in Africa
}

\section{H. A. Wilkins}

AIDS in Africa. Edited by Peter Piot, Bila Kapita and JBO Were. Current Science: 1991. Pp. 209. £35, $\$ 59$ (pbk).

Aids in Africa: Its Present and Future Impact. By Tony Barnett and Piers Blaikie. Belhaven: 1992. Pp. 193. £35 (hbk), £9.99 (pbk).

THE effects of infection with the human immunodeficiency virus (HIV) were first recognized in homosexual men in North America and Europe; 10 years later the developing world faces a massive epidemic of heterosexually spread HIV infection, the effects of which will not become fully apparent for some years. Current estimates suggest that 60 per cent of those infected with HIV may live in Africa, where in some areas infection has already reached appallingly high levels; in these places AIDS is killing large numbers of people in their most productive years and in some hospitals it may be the most common cause of death among adults in medical wards. Yet comparatively few of the resources of the international scientific community working on HIV have been channelled into Africa. This is shown by the recent finding that less than 4 per cent of the papers on HIV in biomedical journals would seem to have discussed the problem of AIDS in Africa. These two complementary publications are therefore most welcome, providing up-to-date accounts of what is known about the epidemiology, effects and possible control of HIV infection in Africa; together, they document the enormous problems posed by the epidemic.

\section{Assessing the impacts}

AIDS in Africa, edited by Piot, Kapita and Were, is a special supplement to the journal $A I D S$. The results of the research that has been done in Africa are scattered widely throughout the scientific literature and much has appeared only in the form of conference abstracts. The 26 authoritative review articles in the supplement are a valuable summary of recent thinking about most aspects of the problems posed by HIV infection, with some emphasis on issues that are of interest to clinicians and epidemiologists. In his foreword, Michael Merson, director of the World Health Organization's global programme on AIDS, comments on the difficulty of visualizing in human terms the meaning of the dry epidemiological statistics that describe the African epidemic. But this task should be easier for readers of Aids in Africa: Its Present and Future Impact by Barnett and Blackie, which is more limited in scope and concentrates on the social, demographic and economic consequences of the infection in one of the worst-affected areas of Uganda, although wider issues are also considered. The authors' account of 18 months of fieldwork in the Rakai district includes detailed descriptions of the complex and tragic ways in which morbidity and mortality due to HIV infection have affected individual families.

Both volumes contain discussions of some of the successful examples of patient care, counselling and prevention programmes. Unfortunately, these are relatively isolated achievements. Most Africans affected by HIV remain without appropriate treatment for opportunistic infections, with only a few of the elite having any access to antiretroviral therapy. The resources for programmes to persuade people to change their sexual behaviour or to encourage them to use condoms do not appear to match those devoted to the marketing of soft drinks or cigarettes. In their review article, Peter Lamptey and Gail A. W. Goodridge acknowledge that in most parts of Africa condoms are either not available or not being used by those who need them.

Barnett and Blaikie realistically point out that the acquisition of knowledge does not necessarily lead to a change in behaviour. They discuss in detail some of the ways in which health education in Uganda may be absorbed into a syncretic view of causality; this can include ideas from traditional beliefs about witchcraft and a fatalistic view of life that allows a rationalization of continued high-risk behaviour. They also consider the problems facing many women in Africa whose position may make it difficult, or impossible, to discuss the use of condoms with their partner or to share the results of an HIV test. It thus is no surprise that in a review of prevention and control strategies, David L. Heymann and Karin Edström anticipate a considerable increase in HIV infection among African adults during the 1990s.

\section{Prospects of a vaccine}

Merson mentions the ray of hope given by the prospect of a vaccine, and it is encouraging to know that the World Health Organization is considering Uganda and Rwanda as sites for vaccine trials. But the development of a vaccine that can be used widely in Africa will

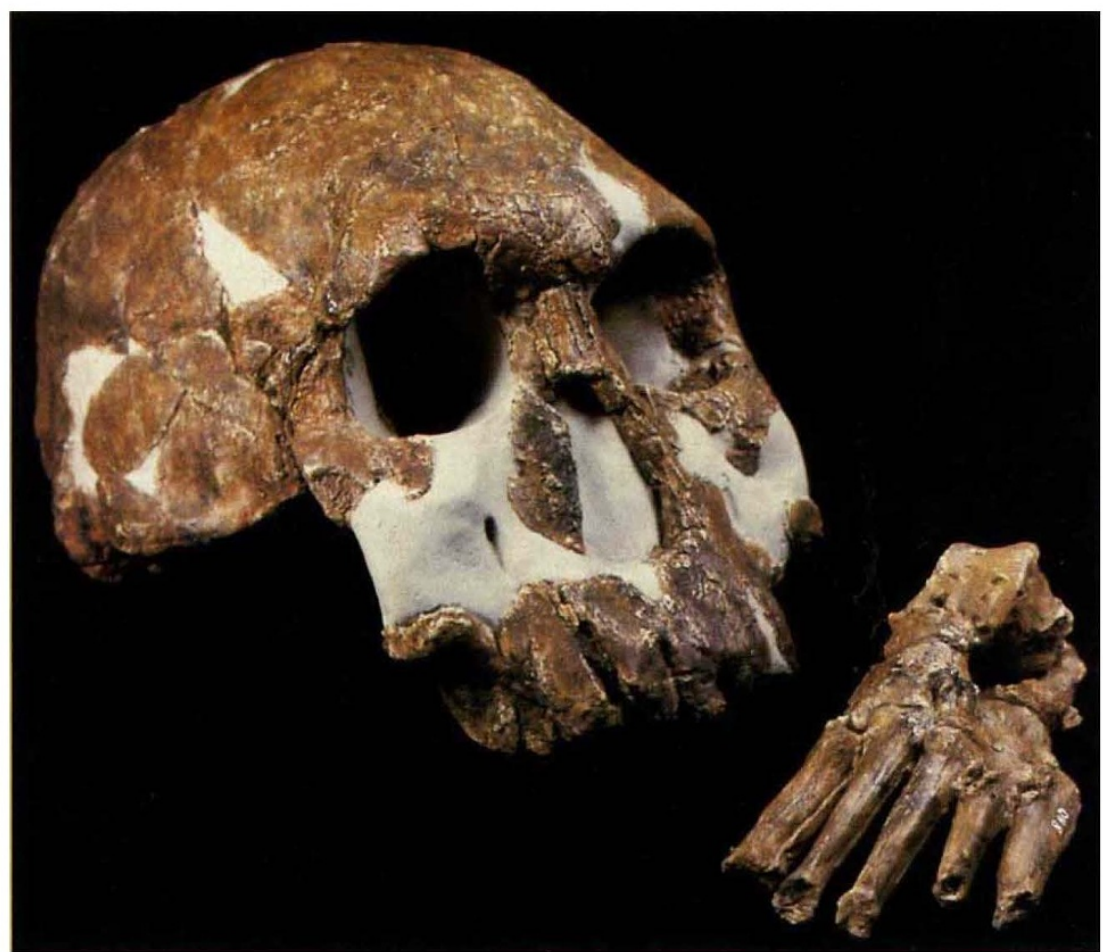

'HANDY-MAN' - The famous skull ER1470 of Homo habilis (Upper Pliocene, about 1.9 million years old) discovered by Richard Leakey in East Turkana, Kenya. This is one of 160 superb colour plates reproduced in Fossils: The Evolution and Extinction of Species by Niles Eldredge, which covers more than 250 different fossil specimens, most taken from the American Museum of Natural History. Published by Aurum, London/Abrams, New York. Price £29.95, $\$ 60$. 